Julio Cesar de Sá da Rocha ${ }^{1}$ Luciana Espinheira da Costa Khoury ${ }^{1}$ Ângela Patrícia Deiró Damasceno²

\title{
DIREITO DAS ÁGUAS - TRAJETÓRIA LEGAL, CONFLITOS E PARTICIPAÇÃO SOCIAL
}

Law of water - legal trajectory, conflicts and social participation

${ }^{1}$ Universidade Federal da Bahia. Salvador/BA, Brasil.

${ }^{2}$ Universidade Federal de Sergipe. Aracaju/SE, Brasil.

Correspondência: Julio Cesar de Sá da Rocha. E-mail: juliorochaufba@gmail.com.

Recebido: 01/05/2017. Revisado: 09/11/2017. Aprovado: 11/11/2017. 


\section{RESUMO}

O presente artigo faz uma breve análise da gestão brasileira de recursos hídricos a partir da política nacional de gestão das águas, transitando por aspectos referentes à previsão normativa, à implementação dos instrumentos de gestão, a alguns dos principais conflitos e à participação social realizada por meio de comitês de bacia hidrográfica, que são os parlamentos das águas, conforme indicado no arcabouço legal. Para tanto, foi realizada uma revisão bibliográfica que inclui autores clássicos e contemporâneos, leis e resoluções, bem como atas de reuniões de organismos de bacia hidrográfica. Os resultados obtidos destacam que a gestão compartilhada das águas, conforme preconizado no marco legal, ainda precisa superar obstáculos de diferentes naturezas para que, de fato, seja efetivada, visto que a equação entre descentralização do poder e participação social ainda demanda ajustes para um equilíbrio de forças.

\section{Palavras-Chave}

Direito ambiental; Gestão de Recursos Hídricos; Participação Social.

\section{ABSTRACT}

This article contains a concise analysis of the Brazilian management of water resources, based on the national water resources management policy, examining aspects related to normative forecasting, implementation of management tools, some of the main conflicts and social participation carried out by the hydrographic basin committees, which are the water resources assemblies, as indicated in the legal framework. For this purpose, a bibliographic review was carried out, which included classic and contemporary authors, laws and resolutions, as well as minutes of meetings of the hydrographic basin related organisms. The results obtained emphasize that shared water management, as recommended in the legal framework, still needs to overcome obstacles of different nature in order to be effective, since the equation between decentralization of power and social participation still requires adjustments for a balance of forces.

\section{Keywords}

Environmental Law; Management and Social Participation; Water Resources. 


\section{Introdução}

Após 20 anos de vigência da Lei Federal n. 9.433/1997 (Lei das Águas) no Brasil, ainda são inúmeras as dificuldades para vivenciar a gestão democrática das águas e implementar os instrumentos de gestão que buscam materializá-la. Esse cenário descortina a realidade de uma normativa calcada em princípios e objetivos compatíveis com o acesso à água em quantidade e qualidade para todos: apesar de ser tomada como um direito fundamental, falta acesso à água decorrente da escassez e da crise hídrica em diversas localidades do país.

Diante da característica de bem essencial à vida, a água precisa ser gerida de maneira participativa e descentralizada, sendo um bem público de uso comum do povo, em que sempre os interesses públicos precisam prevalecer sobre os particulares. No presente artigo, será apresentado breve estado da arte da política nacional de gestão das águas, nos aspectos relacionados à previsão normativa, à implementação dos instrumentos de gestão, a alguns dos principais conflitos e à participação social na gestão das águas por meio de comitês de bacia hidrográfica, que são os parlamentos das águas, conforme indicado no arcabouço legal.

\section{Marco legal da gestão de águas}

A Constituição Federal de 1988 (CF/1988)² inaugura um novo paradigma para a temática ambiental e para a responsabilidade do Estado na promoção de ações que busquem assegurar a efetiva tutela do meio ambiente, trazendo maior exigência de atuação do poder público em matéria de gestão ambiental e hidrográfica. Não resta dúvida de que a constitucionalização da proteção ambiental apresenta-se como um contraponto à crise ambiental mundialmente vivenciada. Se as regras ambientais protetivas fossem efetivamente observadas, provavelmente as condições de vida seriam outras em nosso planeta.

Nesse sentido, Zhouri ${ }^{3}$ revela a incongruência entre os avanços das normativas do país em matéria ambiental e a pouca implementação delas, ao tratar dessa dicotomia no Brasil. Porém, sobre o tema, Canotilho e Leite $e^{4}$ pontuam que a constitucionalização da matéria do ambiente trouxe reflexos na hermenêutica

\footnotetext{
${ }^{1}$ BRASIL. Lei n. 9.433, de 08 de janeiro de 1997. Institui a Política Nacional de Recursos Hídricos, cria o Sistema Nacional de Gerenciamento de Recursos Hídricos, regulamenta o inciso XIX do art. 21 da Constituição Federal, e altera o art. $1^{\circ}$ da Lei n. 8.001, de 13 de março de 1990, que modificou a Lei n. 7.990, de 28 de dezembro de 1989. Disponível em: <http://www.planalto.gov.br/ccivil_03/LEIS/L9433. htm>. Acess em: 10 jan. 2016.

2BRASIL. Constituição da República Federativa do Brasil de 1988. Disponível em: <http://www.planalto.gov. br/ccivil_03/constituicao/constituicaocompilado.htm>. Acesso em: 02 fev. 2018.

${ }^{3}$ ZHOURI, A. Justiça ambiental, diversidade cultural e accoutability - desafios para a governança ambiental. Revista Brasileira de Ciências Sociais, v. 23, n. 68, p. 97-107, out. 2008. Disponível em: <http://www.scielo. br/pdf/rbcsoc/v23n68/v23n68a07.pdf>. http://dx.doi.org/10.1590/S0102-69092008000300007.

${ }^{4}$ CANOTILHO, J. J. G.; LEITE, J. R. M. Direito constitucional ambiental brasileiro. São Paulo: Saraiva, 2007. p. 69.
} 
constitucional e infraconstitucional, como o estabelecimento de um dever genérico de tutela ambiental de não degradar, calcada num regime de explorabilidade limitada e condicionada, modificando a concepção civilista e absolutista do direito de propriedade anteriormente vigente.

Desse modo, nas áreas de tutela do ambiente e das águas no Brasil, a CF/1988 orienta no sentido de promoção de um Estado Constitucional Ambiental, calcado na sustentabilidade e onde o bem ambiental precisa ser por todos cuidado. Para Leite, os elementos a serem observados pelo Estado para sua formação são os seguintes:

a) Buscar formas mais adequadas para a gestão de riscos e evitar a irresponsabilidade organizada; b) Utilizar instrumentos contemporâneos preventivos e precaucionais não apenas diante de danos, mas de riscos abstratos, potenciais e cumulativos; c) Promover efetivo controle ambiental tanto no plano normativo como fático; d) Buscar a formação de uma consciência ambiental; e) Propiciar uma maior compreensão do objeto estudado, tendo o ambiente com as suas diversas dimensões ${ }^{5}$.

No Brasil, o Código de Águas instituído pelo Decreto Presidencial n. $24.643 / 1934^{6}$, disciplinava os usos das águas, sua dominialidade, as competências e os aproveitamentos hídricos. Por essa normativa, existiam águas particulares e águas públicas. Com o advento da $\mathrm{CF} / 1988$, a água passou a ser sempre de domínio público, não sendo recepcionadas as normas infraconstitucionais que estabeleciam a previsão de águas particulares.

Relativizar e condicionar o direito ilimitado à propriedade e aos recursos naturais é uma mudança substancial da ótica civilista. Isso se reflete de maneira intensa na tutela das águas no que se refere à modificação da dominialidade.

Assim, as águas podem pertencer à União, aos estados ou ao Distrito Federal, como dispõem o artigo 20, inciso III, e o artigo 26, inciso I, da CF/1988. Quando a nascente e a foz forem dentro de um mesmo estado, a dominialidade e a gestão competirão ao próprio estado-membro, mas, quando a nascente estiver em um estado e a foz em outro, a dominialidade e a gestão serão da União. Com relação às águas subterrâneas, a dominialidade e a gestão serão sempre do estado.

Conforme o artigo $1^{\circ}$ da Lei n. 9.433/1997 são fundamentos da política nacional de recursos hídricos: (a) a água é um bem público; (b) a água é um recurso natural limitado e com valor econômico; (c) o uso prioritário será o consumo humano e a dessedentação de animais, em caso de escassez; (d) a gestão deverá proporcionar sempre o uso múltiplo; a unidade de planejamento é a bacia

${ }^{5}$ LEITE, José Rubens Morato Leite (Org.) Dano ambiental na sociedade de risco. São Paulo: Saraiva, 2012. p. 151. ${ }^{6}$ BRASIL. Decreto n. 24.643, de 10 de julho de 1934. Decreta o Código de Águas. Disponível em: <http:// www.planalto.gov.br/ccivil_03/decreto/d24643.htm>. Acesso em: 02 fev. 2018. 
hidrográfica; e (e) a gestão dos recursos hídricos deve ser descentralizada e com a participação do poder público, dos usuários e das comunidades. No que se refere à descentralização e ao fato de a bacia hidrográfica ser a unidade de planejamento, Santilli ${ }^{7}$ acredita que a norma incorporou esses fundamentos com amplo respaldo na doutrina especializada e em princípios internacionais, embora sua aplicação prática dependa de uma efetiva articulação entre representantes da União, dos estados, do Distrito Federal, dos municípios e de usuários das águas e organizações civis, sendo este o caminho a ser seguido para uma efetiva gestão de águas que atente ao quanto previsto na política nacional.

Os comitês de bacia hidrográfica previstos pela Lei n. 9.433/1997 são formados por representantes da União, dos estados e do Distrito Federal, dos usuários das águas em sua área de atuação e das entidades civis de recursos hídricos com atuação comprovada na bacia hidrográfica respectiva. Os comitês são os parlamentos das águas, que arbitram os conflitos e deliberam sobre as principais questões relacionadas a cada bacia.

Ainda, de acordo com o artigo $3^{\circ}$ da Lei n. 9.433/1997, são diretrizes gerais de ação para implementação da Política Nacional de Recursos Hídricos:

I - a gestão sistemática dos recursos hídricos, sem dissociação dos aspectos de quantidade e qualidade;

II - a adequação da gestão de recursos hídricos às diversidades físicas, bióticas, demográficas, econômicas, sociais e culturais das diversas regiões do País;

III - a integração da gestão de recursos hídricos com a gestão ambiental;

IV - a articulação do planejamento de recursos hídricos com o dos setores usuários e com os planejamentos regional, estadual e nacional;

V - a articulação da gestão de recursos hídricos com a do uso do solo;

VI - a integração da gestão das bacias hidrográficas com a dos sistemas estuarinos e zonas costeiras.

No que se refere à integração da gestão de recursos hídricos com a de meio ambiente, fica bastante evidente essa necessidade de atuação conjunta, uma vez que os "diversos" danos ambientais ocasionados pelas diferentes atividades produtivas impactam o ambiente e, consequentemente, também impactam as águas. Por essa razão, todas as ações de proteção ambiental possuem reflexos na proteção das águas,

${ }^{7}$ SANTILLI, Juliana Ferraz da Rocha. A Política Nacional de Recursos Hídricos (Lei 9.433/97) e sua implementação no Distrito Federal. Rev. Fund. Esc. Super. Ministério Público Distrito Federal e Territórios, Brasília, ano 9, v. 17, p. 152, jan./jun. 2001. 
e todas as alterações na legislação que estão ocorrendo reduzem a proteção e também afetam a relação das atividades econômicas com as águas.

Propostas de alterações normativas fazem parte de um "pacote" de normas de "flexibilização" da legislação ambiental. Como marcante, destaca-se o Novo Código Florestal, que trouxe graves prejuízos à proteção do ambiente, impactando diretamente a tutela das águas. Em seguida, cita-se a Proposta de Emenda Constitucional (PEC) n. 65/2012, que determina que o próprio poder público é destinatário de norma que viola os princípios da precaução e da prevenção, uma vez que prevê que obras públicas poderão ser implementadas assim que protocolado o Estudo de Impacto Ambiental (EIA). Acredita-se que tamanha violação não encontrará guarida para aprovação. Tramitam no Congresso Nacional e no Conselho Nacional de Meio Ambiente (Conama) diversas propostas, todas elas para "simplificar" e reduzir o escopo do licenciamento ambiental, desprezando a necessidade dos estudos técnicos e da participação social e, por consequência, refletindo de forma direta na proteção das águas.

Pode-se perceber claramente a necessidade de que não sejam dissociados os aspectos da qualidade e da quantidade de água, sendo indispensável considerar ambos os aspectos para atendimento do direito fundamental à água.

Segundo Fachin e Silva , "o relatório de Desenvolvimento Humano de 2006 da ONU concebe a água potável como direito fundamental e, em seguida, conclama a todos os governos para que atuem no propósito de concretizá-lo"9. A crise hídrica é um dos problemas mais graves vivenciados no Brasil e em outros países, sendo presente em diversas regiões nordestinas - com destaque para a região do São Francisco, embora esse grande manancial torne a escassez de água contraditória. Ainda segundo esses autores, "os corpos hídricos das variadas regiões do planeta oferecem água, gradativamente, em menor qualidade e quantidade”. Para Graziera ${ }^{10}$, "a água é considerada o bem mais precioso do século XXI, [mas] vem sofrendo paulatinamente o risco de escassez, em escala mundial, o que constitui um dos principais problemas do milênio".

A situação é agravada diante dos diversos impactos ainda não mensurados, ocasionados pelas diversas atividades produtivas e constituindo algo semelhante ao

\footnotetext{
${ }^{8}$ FACHIN. Zulmar; SILVA Deise Marcelino. Acesso à água potável: direito fundamental de sexta dimensão. 2. ed. Campinas: Milenium, 2012. p. 76.

${ }^{9} \mathrm{Em}$ julho de 2010, a Assembleia da Organização das Nações Unidas editou a Resolução n. 64/292, na qual reconheceu que "o direito à água potável e ao saneamento é um direito humano essencial para a plena fruição da vida e todos os outros direitos humanos" (tradução livre). (No original: "1. Recognizes the right to safe and clean drinking water and sanitation as a human right that is essential for the full enjoyment of life and all human rights;[...]" UNITED NATIONS. Resolution adopted by the General Assembly on 28 July 2010 [without reference to a Main Committee (A/64/L.63/Rev.1 and Add.1)] 64/292. The human right to water and sanitation. Disponível em: <http://www.un.org/ga/search/view_doc.asp?symbol=A/RES/64/292>. Acesso em: 02 fev. 2018.

${ }^{10}$ GRAZIERA, M. L. M. Direito ambiental. São Paulo: Atlas, 2009. p. 184.
} 
que Ulrich Beck denominou de "sociedade de riscos". Segundo Canotilho e Leite": "a sociedade de risco é aquela que, em função de seu contínuo crescimento econômico, pode sofrer a qualquer tempo as consequências de uma catástrofe ambiental [...]". No mesmo sentido Beck ${ }^{12}$, referindo-se à sociedade de riscos, aborda: "no que diz respeito à comoção que produzem, eles (os riscos) já não estão vinculados ao lugar que são gerados - a fábrica. De acordo com o seu feitio, eles ameaçam a vida no planeta sob todas as suas formas". Portanto, os riscos não são suportados apenas pelos tomadores de decisão ou pelo poder público, daí a necessidade ainda mais premente de assegurar a participação social em matéria ambiental e, em especial, na gestão das águas - que, conforme determina a Lei n. 9.433/1997, deverá ser descentralizada e contar com a participação do poder público, dos usuários e da comunidade.

A tarefa é assegurar o acesso à água em quantidade e qualidade para os seres humanos e também para os animais, pois esta é a diretriz prevista na Lei n. 9.433/1997, que diz que devem ter prioridade o consumo humano e a dessedentação animal, em casos de escassez. Não há como implementar essa responsabilidade de outro modo que não considere a descentralização da gestão das águas, pois somente assim poderá haver a melhor decisão a ser adotada pelo poder público, que deve ser voltada a assegurar o acesso à água como direito fundamental pertencente a todos.

Nas reflexões de Rocha ${ }^{13}$, a luta pela proteção da água como bem comum de todos parte do princípio de que esse é um bem coletivo, sendo um direito humano e ambiental. No entanto, sabe-se que o acesso à água não ocorre de maneira justa e igualitária: são as populações vulneráveis as que mais sofrem com a escassez de água, e ainda são as que mais suportam os danos ambientais decorrentes das diversas atividades econômicas. A esse respeito, Pacheco ressalta que:

[...] entretanto, talvez sejam as grandes obras de infraestrutura, como a construção de hidrelétricas e mudanças de curso dos rios, assim como os megaempreendimentos da monocultura, que causam danos irreversíveis à vida de povos indígenas, de remanescentes de quilombos e de populações tradicionais. $\mathrm{Na}$ ocupação desordenada e gananciosa do território, a invasão das monoculturas leva não só à expulsão sumária de alguns desses povos como à diminuição das reservas já existentes e a um confinamento que impede a manutenção de suas tradições, dos seus meios de vida e de sua própria subsistência ${ }^{14}$.

\footnotetext{
${ }^{11}$ CANOTILHO, J. J. G.; LEITE, J. R. M. op. cit., p. 132.

${ }^{12}$ BECK, Ulrich. Sociedade de risco: ruma a uma outra modernidade. 2. ed. São Paulo: Ed. 34, 2011. p. 26.

${ }^{13}$ ROCHA, J. C. S.; SANTANA FILHO, D. M. Justiça ambiental das águas e racismo ambiental. In: JUSTIÇA pelas águas: enfrentamento ao racismo ambiental. Salvador: Gráfica Santa Helena, 2008. p. 37. (Caderno SRH - Serie Água e Ambiente, 2).

${ }^{14}$ PACHECO, T. Racismo ambiental: expropriação do território e negação da cidadania. In: JUSTIÇA pelas águas: enfrentamento ao racismo ambiental. Salvador: Gráfica Santa Helena, 2008. p. 13. (Caderno SRH - Serie Água e Ambiente, 2).
} 
Revela-se desse modo que os grandes empreendimentos disputam água e território com as comunidades tradicionais, muitas vezes invisíveis. Não é difícil perceber que são muitos os resultados desastrosos para as comunidades nessa correlação de forças desiguais. Os impactos ambientais adversos e desproporcionais afetam, sobretudo, povos e comunidades tradicionais, em uma perspectiva de injustiça ambiental. Assim, para atender a todos os usos das águas, de maneira mais equitativa e com justiça ambiental, é necessário o disciplinamento, democratização e controle efetivo dos usos desse bem público, por meio de uma eficiente gestão desses recursos.

\section{As bacias hidrográficas brasileiras e o semiárido}

A distribuição desigual de água no mundo evidencia a necessidade de políticas nacionais e internacionais de gerenciamento e controle de seu uso: $97,5 \%$ da água existente no planeta é salgada e $2,5 \%$, doce, sendo que, destes $2,5 \%$, apenas $0,3 \%$, correspondente à água doce de rios e lagos, é renovável. $\mathrm{O}$ restante está nas calotas polares e nos glaciares, no gelo e na neve das montanhas. Segundo Santilli ${ }^{15}, 60$ países já vivem em guerra pela água, afetando cerca de 232 milhões de pessoas.

O Brasil tem uma situação relativamente privilegiada, pois possui $15 \%$ da água doce existente no planeta. O país conta com uma extensa rede hidrográfica, com seis grandes bacias: Amazonas, Tocantins, São Francisco, Paraná, Paraguai e Uruguai, conforme apontado por Santilli ${ }^{16}$. No entanto, essa distribuição de água nas bacias hidrográficas é bastante diferenciada em cada região. Passam pelo território brasileiro em média cerca de $260 \mathrm{mil} \mathrm{m}^{3} / \mathrm{s}$ de água, dos quais $205 \mathrm{mil} \mathrm{m}^{3} / \mathrm{s}$ estão localizados na bacia do Rio Amazonas, ficando para o restante do território $55 \mathrm{mil} \mathrm{m}^{3} / \mathrm{s}$ de vazão média, segundo informe da Agência Nacional de Águas (ANA) de $2015^{17}$.

Na maioria dos rios da região semiárida brasileira é possível apenas garantir uma oferta contínua de água com o uso de açudes/reservatórios, já que esses rios naturalmente secam durante os meses de estiagem, de acordo com informe da $\mathrm{ANA}^{18}$.

O semiárido brasileiro, no Nordeste, caracteriza-se por vegetação de caatinga, endêmica da flora brasileira, clima com baixa umidade, temperaturas elevadas e chuvas em períodos desordenados. Caracteriza-se também pelo alto índice de evaporação e, portanto, a água possui maior dificuldade de se acumular-se e se infiltrar no solo.

\footnotetext{
${ }^{15}$ SANTILLI, Juliana Ferraz da Rocha. op. cit., p. 144.

${ }^{16}$ Id. Ibid., p. 145

${ }^{17}$ BRASIL. Agência Nacional de Água - ANA. Conjuntura dos recursos hídricos: informe 2015. Brasília-DF: ANA, 2015. p. 23.

${ }^{18}$ Id. Ibid., p. 23.
} 
É necessário, porém, desmistificar que o cenário de escassez e de conflitos crescentes pela água no semiárido é resultado apenas da pouca chuva. Alerta Mal$v e z z i^{19}$ que: "a imagem difundida do semiárido, como clima, sempre foi distorcida. Vendeu-se a ideia de uma região árida, e não semiárida. É como se não chovesse, como se o solo estivesse sempre calcinado, como se as matas fossem secas e a estiagem durasse anos".

Esse cenário se agudiza, em suas múltiplas dimensões, em decorrência da insuficiência na implementação dos instrumentos de gestão de águas e pela ocorrência nas bacias brasileiras de diversos vetores de degradação. O modelo de desenvolvimento vigente, concentrador de terra e água, exploratório, imediatista e pouco comprometido com suas comunidades tradicionais, termina por marcar esse cenário, que contrasta as grandes captações de água e seus pivôs para produzir cada vez mais para a exportação com a lata d'água na cabeça de muitas mulheres do sertão.

Diante de um cenário de crescentes degradações - provocadas pela mineração exploratória, pelo agronegócio para exportação, pela geração de energia e por outras atividades econômicas que impactam as águas em termos de qualidade e quantidade -, têm sido frequentes o desaparecimento de nascentes e riachos, a extinção de espécies da fauna e da flora e a contaminação das águas, bem como a violação de direitos de povos e comunidades tradicionais e a destruição do patrimônio cultural. Paradoxal o fato de que, muitas vezes, é o próprio Estado que implementa ou impulsiona empreendimentos e atividades degradadoras das bacias hidrográficas brasileiras.

Com força, a chamada "indústria da seca" propõe "combater a seca", como se fosse possível, adotando ações inapropriadas e que geram um ciclo que nunca liberta o sertão. Dentre essas medidas, aparecem os carros-pipa e os jegues-pipa, que se eternizam como se fossem solução permanente para determinadas populações. Somem-se a isso grandes obras, como o projeto de transposição do São Francisco que propõe uma solução concentrada em um canal para levar água aos grandes açudes para atender a uma população difusa do Nordeste, cuja concretização é impossível.

Para mudar essa forma de política pública para a gestão de água no semiárido, é preciso conhecer as potencialidades da região, como vêm fazendo a Articulação do Semiárido (ASA) e outros movimentos que propõem a convivência com o sertão, que reconhecem as peculiaridades, as riquezas e as limitações e que respeitam o ambiente, desenvolvendo produtos da biodiversidade das caatingas e fazendo o sertão ser extremamente valorizado e reconhecido. Mas, por certo, é preciso investimento de políticas públicas nessa linha, que valorizem as potencialidades desse sertão.

\footnotetext{
${ }^{19}$ MALVEZZI, R. Semi-árido: uma visão holística. Brasília: Confea, 2007. p. 11.
} 
A solução que vem sendo desenhada e praticada pelas diversas entidades que valorizam o sertão é a convivência com o semiárido, implementando medidas preventivas e continuadas, tais como o armazenando água e sementes para os períodos de escassez. No bojo dessa proposta, é preciso também buscar o acesso à terra e à água para a produção.

Tecnologias sociais vêm sendo desenvolvidas pelas entidades que integram a ASA, sendo elas: a cisterna de placa, a mandala, as barraginhas, as barragens sucessivas e os barreiros, dentre outras. Roberto Malvezzi, ao tratar desse tema, destaca o Programa Uma Terra e Duas Águas:

A proposta básica desse projeto é que as famílias tenham terra suficiente para viver no semiárido e acesso às tecnologias necessárias para captar água para beber e produzir. Mais do que um projeto técnico, é uma estratégia de quem realmente quer mudar a realidade social da região a partir de um novo conceito, o de convivência com o semiárido ${ }^{20}$.

No Brasil, informe da ANA de 2016 (que tem como base o ano de 2015) mostra que as regiões do Atlântico Nordeste Oriental, São Francisco, Parnaíba e Atlântico Leste apresentaram os maiores percentuais de municípios que decretaram situação de emergência em 2015.

Desse modo, é necessário haver uma política pública que garanta o acesso à água para consumo humano e dessedentação animal e para os múltiplos usos, que seja agregadora e que busque atender a todos indistintamente.

\section{Cenário dos instrumentos de gestão e conflitos pelo uso das águas}

Os instrumentos de gestão das águas previstos no artigo $5^{\circ}$ da Lei $n$. 9.433/1997 são:
I - os Planos de Recursos Hídricos;
II - o enquadramento dos corpos de água em classes, segundo os usos preponderantes da água;
III - a outorga dos direitos de uso de recursos hídricos;
IV - a cobrança pelo uso de recursos hídricos;
V - a compensação a municípios;
VI - o Sistema de Informações sobre Recursos Hídricos.

Cada um desses instrumentos possui uma finalidade própria e uma razão de existir, funcionando como peças de uma engrenagem; não é possível que um

\footnotetext{
${ }^{20}$ MALVEZZI, R., op. cit., p. 9.
} 
substitua o outro, e o funcionamento completo dessa engrenagem requer que todos estejam existindo e cumprindo sua função.

Destacando alguns desses instrumentos de forma a identificar sua função, tem-se que o plano de bacia é a base para todos os outros. É nele que está previsto o balanço hídrico entre a disponibilidade de água e a demanda, para que seja possível avaliar quanto de água poderá ser utilizado para os múltiplos usos. É ainda no plano de bacia que, a partir da realidade das atividades que demandam água e de sua disponibilidade, serão eleitas as prioridades de uso para alocações internas e externas.

Esse plano precisa ser construído levando em consideração o diagnóstico da bacia e a previsão dos cenários potenciais dos múltiplos usos, bem como as ações, programas e projetos que devem ser realizados para modificação do cenário encontrado pelo diagnóstico. Para tanto, deve ser elaborado de maneira participativa, envolvendo todos os atores da bacia.

Abordando, por exemplo, os planos de bacias federais: o Plano de Bacia do São Francisco foi elaborado em 2004 e suas atualizações foram concluídas em 2016. Com base no informe da ANA de 2016 (com informações até o ano de 2015), em 2013, iniciou-se a elaboração de três novos planos de recursos hídricos nas bacias hidrográficas do Rio Paraguai, do Rio Grande e do Rio Paranapanema, as duas últimas localizadas na região hidrográfica do Paraná; e o Plano de Bacia do Rio Paraíba do Sul, que foi elaborado em 2007, estava em atualização. Esses planos abrangem 54\% do território, nacional segundo o referido informe da ANA.

Com relação às bacias dos afluentes, a realidade é bastante diferenciada, pois muitas não possuem o instrumento que é a base para outros, a exemplo da outorga. A outorga, por sua vez, é a forma de o poder público controlar os usos e compatibilizá-los com as definições de prioridades e limites previstas no plano de bacia. Caso não haja um plano, a outorga será eventualmente concedida simplesmente pela decisão discricionária do órgão público gestor, e não pela decisão estabelecida pelo comitê de bacia de forma participativa ao condicioná-la às prioridades de uso estabelecidas no plano de recursos hídricos. Ou seja, caso seja concedida outorga em desacordo com o plano e sem observar as prioridades decididas de forma colegiada, há que ser invalidada a autorização de uso da água.

O processo de outorga será realizado pelo órgão da União, a ANA, quando a captação ocorrer na calha de rio federal, ou pelo estado, quando essa captação se der nos cursos d'água estaduais ou em águas subterrâneas. A outorga poderá ser suspensa em razão de descumprimento das condições em que foi concedida ou mesmo por interesse público, estando elencadas na legislação as hipóteses para tanto. Nos casos em que os usos sejam bastante reduzidos, poderão ser dispensados de outorga; no entanto, esse procedimento ocorre de igual maneira perante o órgão gestor; o processo tramita, para então concluir, se for o caso, pela dispensa de outorga, mas o usuário terá tornado público o uso que faz das águas para o controle estatal. 
Para Viegas ${ }^{21}$, nas hipóteses em que a suspensão ou revogação das outorgas decorra da não observância das condições em que foi concedida, deverá ser sempre observado o direito ao devido processo legal, com ampla defesa e contraditório. Entretanto, nos casos em que seja suspensa ou revogada por interesse público, não há que se falar nessa necessidade, tendo em vista a existência da Súmula 473 do Supremo Tribunal Federal (STF), que indica que a administração pública pode rever seus próprios atos quando eivados de vícios que os tornem ilegais.

Ainda de acordo com Viegas ${ }^{22}$, não há obrigatoriedade de concessão da outorga ao particular. A exceção é aquela em que está se pleiteando água para consumo humano ou dessedentação animal e não havendo outra forma alternativa, na interpretação sistêmica que faz do artigo $1^{\circ}$, inciso III, da Lei n. 9433/1997.

Porém, nos casos em que os fins forem econômicos, não é possível considerar como se os empreendimentos possuíssem direito subjetivo à outorga, pois, como afirmado, tudo será relativizado a partir das prioridades de uso definidas no plano de bacia.

Segundo informe da ANA de $2016^{23}$, o órgão emitiu 1.435 outorgas de usos consuntivos $^{24}$ no período de agosto de 2014 a julho de 2015, totalizando uma vazão de $224,28 \mathrm{~m}^{3} / \mathrm{s}$. O destaque no ano de 2015 foi a emissão da outorga aos usuários do Rio Verde Grande com racionamento do uso (diminuição de horas de captação diária), de acordo com o nível d'água da estação fluviométrica ${ }^{25}$.

Com relação aos estados, o instrumento de outorga de direito de uso de recursos hídricos já foi implementado em 24 dos 27 da Federação. Os estados do Amapá, Amazonas e Mato Grosso do Sul não têm emitido outorgas de recursos hídricos. O Estado do Acre começou a outorgar o uso dos recursos hídricos sob sua dominialidade no ano de 2015. Por exemplo, na Bacia do São Francisco existe o instrumento de outorga, porém, sua implementação tem sido feita de forma bastante insatisfatória em razão de existirem pouquíssimos planos de bacia em seus afluentes. Em sua grande maioria, as outorgas são todas discricionárias, com análise estimativa do volume de água outorgada. E mais: sem identificar o contexto da região, são feitas de maneira estanque, apenas considerando a quantidade de água em determinado corpo hídrico, mas sem levar em conta os impactos produzidos no entorno ou mesmo os efeitos sinérgicos. Ainda, são inúmeros os usos clandestinos, podendo-se afirmar a existência de descontrole nas captações de água bruta

\footnotetext{
${ }^{21}$ VIEGAS, Eduardo Coral. Visão jurídica da água. Porto Alegre: Livr. do Advogado Ed., 2005. p. 99.Id. Ibid., p. 104.

${ }^{22}$ ld. Ibid. loc. cit.

${ }^{23}$ BRASIL. Agência Nacional de Água - ANA. Conjuntura dos recursos hídricos: informe 2015, cit., p. 79.

${ }^{24}$ Entende-se por usos consuntivos aqueles usos em que há perda da água que é retirada do corpo hídrico, como no caso de abastecimento humano e industrial e na irrigação.

${ }^{25}$ BRASIL. Agência Nacional de Água - ANA. Conjuntura dos recursos hídricos: informe 2015, cit.
} 
em especial, em casos de captações de águas subterrâneas - resultando inclusive na grande exploração de aquíferos como no caso do Urucuia, sem controle e monitoramento efetivo de competência do órgão estadual.

Os resultados das outorgas desmedidas, sem análise técnica de capacidade de suporte por meio do balanço hídrico, são sentidos pela redução no volume dos rios, pelo desaparecimento de nascentes e riachos e pela redução na lâmina de água dos rios, além de diversas outras consequências que terminam por afetar o ecossistema aquático e as comunidades tradicionais em seus usos.

Reflete bem o contexto de outorgas sem plano de bacia no São Francisco o pensamento de Roberto Malvezzi:

Muitas vezes, a outorga tem se prestado mais à legalização da
apropriação privada que à normatização e disciplinamento de
uso. [...] Portanto, o instrumento de outorga pode funcionar
adequadamente, mas depende também da ação do poder público
e da pressão social sobre o uso da água ${ }^{26}$.

A cobrança pelo uso dos recursos hídricos, por sua vez, tem como objetivo a racionalização do uso da água e a obtenção de recursos para realizar as ações, os planos e as programas previstos no plano de bacia, nos moldes previstos na Lei n. 9433/1997. A cobrança está condicionada à existência de outorga, que lhe é precedente, seja ela provisória, seja definitiva. Ressalte-se que esse instrumento previsto na lei deve levar em consideração os diferentes usos da água, uma vez que não deve ser fator prejudicial ao acesso. Ao contrário, destina-se a racionalizar o uso dos grandes usuários, fazendo retornar recursos para cuidar da bacia. Porém, para aquelas comunidades que utilizam a água apenas para sua subsistência - as comunidades tradicionais - por certo não deverá ter a incidência de tal cobrança.

Em alguns estados, como Minas Gerais, a legislação estadual condiciona a cobrança à existência de plano de bacia; em outros, como na Bahia, não há essa exigência, porém, tal circunstância está sendo debatida no âmbito dos comitês. $\mathrm{O}$ comitê de bacia é quem indica para o conselho a proposta de valores a serem efetuados na cobrança pelo uso dos recursos hídricos.

Grande parte das bacias federais já possui esse instrumento, como são os casos das bacias do São Francisco, do Paraíba do Sul e do Verde Grande. Por outro lado, na maioria das bacias estaduais ainda não está implementado o instrumento da cobrança, conforme registrado no informe da ANA de 2016.

Por exemplo, no caso do Rio São Francisco, está sendo realizada a cobrança desde 2010, com relação às outorgas da calha do rio. Com os recursos arrecadados

${ }^{26}$ MALVEZZI, R. op. cit., p. 101. 
com a cobrança, é elaborado plano de aplicação plurianual, conforme os aspectos diagnosticados e indicados no plano de bacia. Com o advento da cobrança, foi aperfeiçoada a atuação do Comitê da Bacia Hidrográfica do Rio São Francisco (CBHSF), que passou a ter maior autonomia para realizar reuniões, capacitações, encontros para debates e deliberações, contando com assessoria técnica e jurídica, além de poder decidir coletivamente onde os recursos serão aplicados, como ações estratégicas para a bacia.

O instrumento do enquadramento dos corpos d'água segundo os usos preponderantes, que visa a estabelecer metas de qualidade da água para atender aos usos preponderantes da bacia hidrográfica, deve ser aprovado pelos conselhos de recursos hídricos (estadual ou federal). As bases legais para estabelecer o enquadramento são: as resoluções do Conama n. 357/2005 ${ }^{27}$, n. 396/2008 ${ }^{28}$ e n. 397/2008 ${ }^{29}$; e as resoluções do Conselho Nacional de Recursos Hídricos (CNRH) n. 91/2008 ${ }^{30}$ e n. 141/2012 ${ }^{31}$.

Quando ainda não houver o enquadramento, todos os rios devem ser considerados classe 2, conforme determinado na legislação. Segundo informe da ANA de $2016^{32}$, no ano de 2015 não foram feitos enquadramentos de corpos d'água de rios federais, mas foram feitos o do Baixo Jacuí, no Rio Grande do Sul, e o do Rio Benevente, no Espírito Santo.

O sistema de informações em nível federal é bastante avançado, com manuais como o Informe Anual da ANA e demais informações disponibilizadas por meio virtual, ampliando o conhecimento para toda a população. No entanto, muitos estados ainda não implementaram esse instrumento.

\footnotetext{
${ }^{27}$ BRASIL. Conselho Nacional do Meio Ambiente - CONAMA. Resolução n. 357, de 17 de março de 2005. Dispõe sobre a classificação dos corpos de água e diretrizes ambientais para o seu enquadramento, bem como estabelece as condições e padrões de lançamento de efluentes, e dá outras providências. Disponível em: <http://www.mma.gov.br/port/conama/legiabre.cfm?codlegi=459>. Acesso em: 02 fev. 2018.

${ }^{28}$ BRASIL. Conselho Nacional do Meio Ambiente - CONAMA. Resolução CONAMA N n. ${ }^{\circ} 396$, de 3 de abril de / 2008. Dispõe sobre a classificação e diretrizes ambientais para o enquadramento das águas subterrâneas e dá outras providências. Disponível em: <http://www.mma.gov.br/port/conama/legiabre. cfm?codlegi=562>. Acesso em: 02 fev. 2018.

${ }^{29}$ BRASIL. Conselho Nacional do Meio Ambiente - CONAMA. Resolução n. 397, de 7 de abril de 2008. Altera o inciso II do $\S 40$ e a Tabela X do § 5o, ambos do art. 34 da Resolução do Conselho Nacional do Meio AmbienteCONAMA n. 357, de 2005, que dispõe sobre a classificação dos corpos de água e diretrizes ambientais para o seu enquadramento, bem como estabelece as condições e padrões de lançamento de efluentes. Disponível em: <http://www.mma.gov.br/port/conama/legiabre.cfm?codlegi=563>. Acesso em: 02 fev. 2018.

${ }^{30}$ BRASIL. Conselho Nacional de Recursos Hídricos - CNRH. Resolução n. 91, de 05 de novembro de 2008. Dispõe sobre procedimentos gerais para o enquadramento dos corpos de água superficiais e subterrâneos. Disponível em: <http://portalpnqa.ana.gov.br/Publicacao/RESOLU\%C3\%87\%C3\%830\%20CNRH\%20 n\%C2\%BA\%2091.pdf>. Acesso em: 02 fev. 2018.

${ }^{31}$ BRASIL. Conselho Nacional de Recursos Hídricos - CNRH. Resolução n. 141, de 10 de julho de 2012. Estabelece critérios e diretrizes para implementação dos instrumentos de outorga de direito de uso de recursos hídricos e de enquadramento dos corpos de água em classes, segundo os usos preponderantes da água, em rios intermitentes e efêmeros, e dá outras providências. Disponível em: <http://www.cnrh.gov. br/index.php?option=com_content\&view=article\&id=14>. Acesso em: 02 fev. 2018.

${ }^{32}$ BRASIL. Agência Nacional de Água - ANA. Conjuntura dos recursos hídricos: informe 2016. Brasília-DF: ANA, 2016. p. 76.
} 
Por certo que, sem instrumentos de gestão instalados e em adequado funcionamento, o comitê de bacia hidrográfica fica à mercê de um jogo político de liberação dos recursos para funcionamento do próprio sistema de gestão compartilhada. A partir daí, e não somente disso, principalmente quando é analisado o cenário de escassez hídrica, iniciam-se ou acirram-se os conflitos, aqui entendidos como divergências sobre as ações apropriadas a serem realizadas em uma determinada situação. Conflitos ocorrem na medida em que indivíduos ou grupos de indivíduos têm diferentes valores, prioridades, interesses e objetivos futuros. Eles (os conflitos) podem ocorrer entre vizinhos, comunidades, estados, regiões e nações. Em relação à água, os conflitos tendem a ocorrer quase sempre em situações de escassez.

Os conflitos gerados pelo uso da água têm sido registrados na história das civilizações humanas desde a Antiguidade. Os ciclos de cheias e secas e as variações espaciais de disponibilidade de água ocorrem normalmente na natureza. Esses fenômenos naturais passam a ter impactos na sociedade à medida que ocorre o crescimento das populações e das atividades humanas. Os conflitos ocorrem pela dificuldade em compatibilizar, no espaço e no tempo, o crescimento econômico com a conservação ambiental, a qualidade de vida, a disponibilidade hídrica e a equidade social.

Alguns dos principais conflitos pelo uso das águas no Brasil podem ser destacados. A situação de escassez de água que vem sendo diariamente noticiada pelos meios de comunicação na Bacia do São Francisco - atingindo, por exemplo, seu maior reservatório, que é a Barragem de Sobradinho - chegou a apresentar apenas $1,1 \%$ de seu volume, conforme noticiado pelo $\mathrm{CBHSF}^{33}$. O volume de água vem sendo reduzido consideravelmente em seu leito. Nesse contexto, o plano de bacia vigente prevê a liberação de $1.300 \mathrm{~m}^{3} / \mathrm{s}$ como vazão ambiental - valor mantido na atualização do plano - para que exista um equilíbrio do rio ao chegar ao mar e para que a foz possua condições adequadas à manutenção de um equilíbrio ecológico.

Porém, diante dessas multiplicidades de vetores que vêm diminuindo sobremaneira a quantidade de água dos reservatórios, a ANA e o Instituto Brasileiro do Meio Ambiente e dos Recursos Naturais Renováveis (Ibama), atendendo a pedido do Operador Nacional do Sistema Elétrico (ONS), vêm sistematicamente autorizando a Companhia Hidrelétrica do São Francisco (CHESF) a reduzir progressivamente para $1.100 \mathrm{~m}^{3} / \mathrm{s}, 1.000 \mathrm{~m}^{3} / \mathrm{s}, 900 \mathrm{~m}^{3} / \mathrm{s}, 800 \mathrm{~m}^{3} / \mathrm{s}, 700 \mathrm{~m}^{3} / \mathrm{s}, 600 \mathrm{~m}^{3} / \mathrm{s}$ e, atualmente, $550 \mathrm{~m}^{3} / \mathrm{s}$, já indicando possibilidade de redução ainda maior na vazão a jusante de Sobradinho. Essa situação leva a um efetivo conflito no uso das águas, pois, quando a vazão ambiental é reduzida, a região chamada Baixo São Francisco (que abrange os estados da foz) sofre as consequências ecológicas e sociais, uma vez que o rio não

\footnotetext{
${ }^{33}$ AGONIA do Velho Chico aumenta com vazão ainda menor. Comitê da Bacia Hidrográfica do Rio São Francisco - CBHSF, 22.12.15. Disponível em: <http://cbhsaofrancisco.org.br/2017/agonia-do-velho-chicoaumenta-com-vazao-ainda-menor/>. Acesso em: 09 jan. 2016.
} 
chega no mar e é o mar que adentra o rio. Existe "sala de situação", com reuniões periódicas e gerida pela ANA, para discutir o problema semanalmente, funcionando como centro de gestão de situações críticas e subsidiando a tomada de decisões da diretoria colegiada da ANA.

Destaca-se a situação vivenciada pela bacia hidrográfica do Rio Paraíba do Sul, que tem destacada importância no cenário nacional por estar localizada entre os maiores polos industriais e populacionais do país e pelo processo que envolve o gerenciamento de seus recursos hídricos. Caracteriza-se pelo peculiar desvio das águas para a bacia hidrográfica do Rio Guandu, com a finalidade de geração de energia e abastecimento de cerca de nove milhões de pessoas na Região Metropolitana do Rio de Janeiro, formando o Sistema Hidráulico do Rio Paraíba do Sul, um intrincado e complexo conjunto de estruturas hidráulicas que interliga as bacias hidrográficas dos rios Paraíba do Sul e Guandu.

Com a escassez hídrica que vem enfrentando a bacia do Rio Paraíba do Sul, a ANA, desde maio de 2014, editou diversas resoluções autorizando, temporariamente, a redução da vazão mínima de defluências dos seus reservatórios, com vistas a preservar o estoque de água disponível nos reservatórios, de acordo com o informe da $\mathrm{ANA}^{34}$.

Observa-se que, nos casos do São Francisco e do Paraíba do Sul, as medidas adotadas estão voltadas apenas para a operação de reservatórios e desconsideram que a situação vivenciada pelas bacias não é apenas causada pela escassez de chuva, sendo este um dos relevantes fatores, mas não o único. Desse modo, entende-se que, para o enfrentamento da crise hídrica identificada na Bacia do São Francisco e na Bacia do Paraíba do Sul, torna-se indispensável um plano de atuação para conter os danos às bacias e suas águas, bem como adotar medidas de implementação de instrumentos de gestão e de racionamento e controle dos usos das águas nas bacias. Alguns desses conflitos já estão formalizados perante os respectivos Comitês e outros, ainda não.

\section{Comitês de bacia e participação social}

Ao se discutir participação social no âmbito da gestão dos recursos hídricos, é preciso compreender os pilares teóricos de sustentação que serão utilizados. Nesse sentido, deve-se partir da premissa de que é imprescindível destacar que a participação social existente no marco regulatório da gestão das águas no Brasil se dá num âmbito representativo e deliberativo - tal qual descrito em alguns dos principais modelos teóricos de democracia, destacados por $\mathrm{Nobre}^{35}$, que afirma ser o

\footnotetext{
${ }^{34}$ BRASIL. Agência Nacional de Água - ANA. Conjuntura dos recursos hídricos: informe 2016, cit., p. 49.

${ }^{35}$ NOBRE, M. Participação e deliberação na teoria democrática: uma introdução. In: COELHO, V.S.P.; NOBRE, M. (Orgs.). Participação e deliberação: teoria democrática e experiências institucionais no Brasil Contemporâneo. São Paulo: Ed. 34, 2004. p. 134.
} 
modelo deliberativo o que concentra o maior número de adeptos contemporâneos. Segundo Habermas ${ }^{36}$, o modelo de democracia deliberativa está organizado em torno de um ambiente de justificativa, de argumentação pública livre entre iguais. Nesse ambiente, um processo de deliberação precisa respeitar a participação de todos com simetria e igualdade de acesso, de construção do formato, dos argumentos e da forma de votação. Na democracia moderna, originada como democracia representativa, evidencia-se a necessidade de um contraponto à "representação do interesse".

A promoção de espaços que contribuam para discussões e deliberações representa o avanço democrático dos governos que compartilham desse regime político. Trata-se de uma das demandas dos movimentos sociais que, segundo Abers e Bolow $w^{37}$, têm se mobilizado em prol de mudanças nos processos de tomada de decisão estatal, demandando a inclusão da sociedade civil em novos espaços participativos.

No Brasil, para Flores e Misoczky $y^{38}$, a participação social surgiu como uma maneira de garantir práticas mais igualitárias, sugerindo uma mudança qualitativa na gestão. Esse processo foi decorrente das mudanças ocorridas no país após a instalação da democracia: a sociedade civil passou por um período de transformações e foram criados espaços de interação que configuraram uma sociedade mais ativa e organizada.

A descentralização e a criação de mecanismos participativos também são reivindicações características de um processo de democratização; segundo Tatagiba ${ }^{39}$, mesmo que entre a sociedade civil e o governo exista uma igualdade numérica, essa igualdade não é suficiente para garantir o equilíbrio no processo decisório, e acrescenta: “[...] as instituições civis também se apropriam das regras "não escritas" do jogo de negociação e muitas vezes ocupam vacâncias ou assentos de câmaras técnicas na perspectiva de garantir visibilidade às suas ações e não por que acreditam no sistema."

Habermas $^{40}$ reintroduz a questão democrática por um aspecto participativo e social, em que todos os cidadãos podem ter oportunidade de expressão. Ele ainda aponta para a necessidade de se garantirem aos cidadãos direitos de comunicação e direitos de participação política, visando, inclusive, à própria legitimidade do processo legislativo. Explica o autor que, na medida em que os direitos de comunicação

\footnotetext{
${ }^{36}$ HABERMAS, J. Era das transições. Tradução de Flávio Beno Siebeneichler. Rio de Janeiro: Tempo Brasileiro, 2003 p. 128.

${ }^{37} \mathrm{ABERS}$, Rebecca; BULOW, Marisa Uon. Movimentos sociais na teoria e na prática: como estudar o ativismo através da fronteira entre Estado e sociedade. Sociologias, Porto Alegre, v. 13, n. 28, p. 57, set./dez. 2011. Disponível em: <http://www.scielo.br/pdf/soc/v13n28/04.pdf>. http://dx.doi.org/10.1590/S1517-45222011000300004.

${ }^{38}$ FLORES, Rafael Kruter; MISOCZKY, Maria Ceci. Participação no gerenciamento de bacia hidrográfica: o caso do Comitê Lago Guaíba. Rev. Adm. Pública, Rio de Janeiro, v. 42. n. 1. p. 82, jan./fev. 2008. Disponível em: <http:// www.scielo.br/pdf/rap/v42n1/a06v42n1.pdf>. http://dx.doi.org/10.1590/S0034-76122008000100006.

${ }^{39}$ TATAGIBA, Luciana. Os conselhos gestores e a democratização das políticas públicas no Brasil. In: DAGNINO, Evelina (Org.). Sociedade civil e espaços públicos no Brasil. São Paulo: Paz e Terra, 2004. p. 116.

${ }^{40}$ HABERMAS, J. op. cit., p. 139.
} 
e de participação política são constitutivos para um processo de legislação eficiente do ponto de vista da legitimação social, esses direitos não podem ser tidos como os de entes jurídicos privados e isolados: eles têm que ser apreendidos no enfoque de participantes orientados pelo entendimento, que se encontram numa prática de entendimento. Nesse sentido, só é legítimo "aquilo em torno do qual os participantes da deliberação livre podem unir-se por si mesmos, sem depender de ninguém para tradução do discurso".

Para vários autores - Nobre ${ }^{41}$, Lopes $^{42}$, Dagnino ${ }^{43}$-, as dificuldades mais encontradas em instâncias participativas, como conselhos de meio ambiente e audiências públicas de estudos de impacto ambiental, são: as discussões intermináveis; a falta de quórum nas plenárias; as pautas extensas; as atas que não são lavradas; a paridade ou a falta dela na composição dos conselhos; a fragilidade da representação institucional; a descontinuidade e o descompromisso dos representantes; a falta de apoio ou de condições de participação para pessoas ou organizações realmente interessadas; os diferentes níveis de informação e qualificação; o gigantismo da estrutura de uns, em contraste com a fragilidade e desorganização de outros; a manipulação da participação; e a cooptação dos representantes em razão de todas essas dificuldades.

Quando a Lei n. 9.433/1997 estabelece que a gestão de água será descentralizada e participativa, essa diretriz precisa ser respeitada, uma vez que cada bacia possui suas especificidades, não sendo possível generalizar decisões. A tomada de decisão depende de todas as peculiaridades da realidade e da pactuação que se estabelece entre os representantes dos múltiplos usos da água em cada bacia hidrográfica. Para tanto, se faz necessária a criação de espaços concretos de discussão, com condições para a materialização dessa participação, democratizando as decisões e os riscos. O poder público deve se comprometer em assegurar os meios necessários ao envolvimento dos demais segmentos, com destaque para os representantes da sociedade civil e pequenos usuários.

O CBHSF, sem dúvida, é uma das referências quando o aspecto analisado é a formação plural dos membros. Atualmente, o Comitê da Bacia do São Francisco comporta entre seus membros representantes indígenas, pescadores e quilombolas. Essas representações das comunidades tradicionais têm no CBHSF mais um espaço de busca de direitos, valorização e reconhecimento, pois, segundo Roch $a^{44}$, a gestão dos recursos hídricos não passa apenas pela decisão daqueles que operam os sis-

\footnotetext{
${ }^{41}$ NOBRE, M. op. cit.

${ }^{42}$ LOPES, José Sérgio Leite. Sobre processos de "ambientalização" dos conflitos e sobre dilemas da participação. Horizontes Antropológicos, Porto Alegre, v. 12, n. 25, p. 31-64, jan./jun. 2006. Disponível em: <http://www. scielo.br/pdf/ha/v12n25/a03v1225.pdf>. http://dx.doi.org/10.1590/S0104-71832006000100003.

${ }^{43}$ DAGNINO, Evelina (Org). Sociedade civil e espaços públicos no Brasil. São Paulo: Paz e Terra. 2004.

${ }^{44}$ ROCHA, J. C. S.; SERRA, O. (Orgs.). Direito ambiental, conflitos socioambientais e comunidades tradicionais. Salvador: EDUFBA, 2015. p. 406.
} 
temas de abastecimento ou saneamento; ao se abrir a comporta de uma barragem, deve-se pensar nos povos étnicos que vivem à margem dos rios. Afinal, quem vem decidindo por eles?

Segundo Medeiros ${ }^{45}$, estamos diante de uma descentralização na gestão de águas, mas não de uma democratização, que há de ser perseguida e implementada para uma efetiva governança das águas do Rio São Francisco. Cabe destacar que a descentralização, apesar de constituir um dos princípios para a democratização da gestão das águas, prescinde de formação e qualificação dos representantes de comitês de bacia, bem como demanda uma estrutura que viabilize a regularidade dos encontros e reuniões para a apreciação de conflitos e condições de uso das águas de cada bacia hidrográfica.

Muitos comitês dos afluentes não vêm tendo apoio para seu funcionamento, como se pode ver pelas incipientes condições de tomada de decisão que detêm, seja em razão da pouca qualificação técnica de seus integrantes, seja pela limitada estrutura para realização das reuniões plenárias, onde as deliberações devem ocorrer.

Sem dúvida, o fortalecimento dos comitês de bacia em seu relevante papel conferido pela Lei das Águas é condição efetiva para que essa governança das águas aconteça a contento. Conforme Ribeiro ${ }^{46}$, as condições para que a governança possa ocorrer são: “a mobilização social, capacidade de assimilação do Estado de decisões externas a ele, e criação e existência de instrumentos jurídicos que possibilitem que a participação social ganhe legitimidade”.

Como dito, o comitê de bacia é órgão colegiado formado por representantes do poder público, dos usuários e da sociedade civil que possui interesses e objetivos; porém, diante das competências elencadas pela Lei n. 9.433/1997 em seu artigo 38, não há como deixar de dialogar exaustivamente com representantes de múltiplos usos e diferentes segmentos e categorias. Nesse espaço, são importantes os conhecimentos técnicos, mas também são indispensáveis os olhares das comunidades que conhecem o rio e todas as suas nuances. Os diversos saberes precisam ser valorizados, não havendo hierarquia entre os mesmos.

A dinâmica de participação nos comitês de bacia prevê igualdade de condição. No entanto, essa situação, na prática, termina por ser afetada quando não são asseguradas as condições materiais de participação da sociedade civil, ou mesmo o assessoramento necessário aos membros do comitê de bacia em determinados aspectos relevantes.

\footnotetext{
${ }^{45}$ MEDEIROS, Y. Participação social no gerenciamento de recursos hídricos: a bacia do São Francisco. São Paulo: ANABLUME, FAPESP, 2009. p. 95.

${ }^{46}$ RIBEIRO, W. C. (Org.). Governança da água no Brasil: uma visão interdisciplinar. 1. ed. São Paulo: ANABLUME. FAPESP, 2009. p. 117.
} 
Segundo Damasceno, essa logística, juntamente com o acesso à informação e o tempo adequado para análise de conjunturas e estabelecimento de consensos, mostram-se importantes elementos de atenção para assegurar a participação social - além de constituírem condições de viabilidade para o funcionamento do comitê, com todas as suas missões e responsabilidades.

Os comitês de bacia são, de forma geral, estruturas comprometidas com a defesa hidroambiental, mas passam por diversas dificuldades que vão desde a logística de um local para realização das reuniões plenárias e elaboração de uma ata até a assessoria jurídica e técnica para redação de suas deliberações e notas técnicas, bem como espaços para formação e qualificação de seus membros.

Recentemente, o Comitê da Bacia Hidrográfica do Rio Doce (CBH-Doce) ganhou grande visibilidade após a tragédia de Mariana (Minas Gerais); todavia, o colegiado vem ressaltando em vários meios de comunicação a dificuldade de participar e de ser respeitado quanto às decisões tomadas em relação à recuperação do manancial e à aplicação da multa imposta à mineradora Samarco. O CBH-Doce conseguiu ser incluído no comitê interfederativo e no conselho deliberativo que decidirão sobre a aplicação dos recursos oriundos da sanção importa à empresa Samarco; porém, não conseguiu exercer sua atribuição de árbitro de conflitos e tomador de decisão a respeito da bacia hidrográfica atingida.

Esse cenário de pouco apoio efetivo aos comitês de bacia e de reais dificuldades tem levado à falta de estímulo de diversos membros, sendo um grande desafio obter a participação nesse espaço colegiado de tanta relevância nacional.

Sem dúvida, a participação social fortalece a capacidade de crítica e de interveniência dos segmentos mobilizados, por meio de um processo informativo e interativo. Entretanto, a instalação dos comitês de bacia hidrográfica tem sido objeto de questionamentos, sobretudo pela imprecisão dos conceitos de participação e controle social. O termo "participativo" entrou para os discursos governamentais, de forma que as negociações passaram a ser trabalhadas conjuntamente entre leigos e especialistas, sem necessariamente respeitar uma composição de saberes popular e técnico a respeito da gestão das águas e, muito menos, sem uma perspectiva de garantir que os múltiplos usos (inclusive a preservação ambiental) tenham voz ativa e igualitária nos comitês de bacia. Dessa forma, a gestão colegiada tende a definir uma dinâmica que permite que os atores integrem e ajustem suas práticas com base em uma lógica de negociação que substitui uma concepção tecnocrática, visando a ajustar interesses e propostas nem sempre convergentes e articulados para um objetivo comum ${ }^{47}$.

\footnotetext{
${ }^{47}$ GUIVANT, Júlia Silva; JACOBI, Pedro Roberto. Da hidro-técnica à hidro-política: novos rumos para a regulação e gestão dos riscos ambientais no Brasil. Cadernos de Pesquisa Interdisciplinar em Ciências Humanas, Florianópolis, v. 4, n. 43, p. 2-26, jan. 2003. Disponível em: <https://periodicos.ufsc.br/index.php/ cadernosdepesquisa/article/view/1950>. https://doi.org/10.5007/1950.
} 
Um fator de desestímulo aos comitês de bacia é o desrespeito a suas deliberações. Não restam dúvidas de que, como decisão colegiada, legítima e respaldada no regramento legal, não deve ser descumprida pelo poder público, que deverá se submeter à mesma. A prática do controle social e da participação na gestão das águas precisa ser necessariamente ressignificada, com a percepção por todos os atores sociais de que, sem esses requisitos, não se alcançará a efetiva governança das águas, chegando a comprometer o funcionamento do sistema de gestão integrada de recursos hídricos na perspectiva da gestão compartilhada.

\section{Considerações Finais}

A água é um bem público de uso comum do povo. Como tal, necessita ser gerida de modo a atender aos interesses públicos acima de qualquer interesse particular, e o acesso a ela é um direito fundamental. Essas são as orientações previstas em nossa CF/1988, quando enuncia o Estado Constitucional Ambiental. Embora exista uma normativa constitucional e legal apontando para o exercício da implementação de um sistema de gestão de águas que seja descentralizado e participativo, por meio dos comitês de bacia, e que promova a efetiva gestão com a implementação de seus instrumentos, constata-se uma verdadeira lacuna na materialização desses imperativos normativos.

A insuficiência dos instrumentos de gestão, seja na calha, seja nos afluentes (que são de responsabilidade dos estados), contribui para a crise hídrica atualmente vivenciada em bacias federais, como nas bacias do São Francisco, do Paraíba do Sul e tantas outras. Essa crise não é apenas ocasionada por fatores climáticos de escassez de chuva; não se pode atribuir a uma causalidade única a situação de escassez de água e da qualidade da água das bacias hidrográficas brasileiras.

Ao contrário, trata-se de um conjunto de causas que terminam por gerar a crise hídrica e, com ela, o acirramento de conflitos de uso e de violações do direito de tantas comunidades e populações ao acesso à água. Essas causas precisam ser enfrentadas, o que passa pela busca concreta da democratização na gestão das águas e pela implementação efetiva dos instrumentos de gestão.

Contribuem, ainda, de forma decisiva para o cenário descrito os diversos vetores de degradação que impactam o ambiente e as águas, pois são direta e sistematicamente interligados. São muitas as atividades desenvolvidas nas bacias, geradoras de impactos ambientais e que precisam de maior controle e restrições. A variável socioambiental precisa ser compreendida como parte do processo de toda e qualquer atividade produtiva nas bacias. É preciso reorientar o modelo de desenvolvimento de modo a compatibilizá-lo com o equilíbrio e a sustentabilidade para a presente e as futuras gerações Para tanto, é necessário enxergar o rio para além de um curso d'água sem vida e que se pode explorar até a exaustão. 
Em suma, após 20 anos de vigência da Política Nacional de Recursos Hídricos, instituída pela Lei n. 9.433/1997, há muito o que se fazer até que se possam vislumbrar horizontes de diálogo para sua efetiva aplicação, principalmente diante da relevância indiscutível da questão hídrica, em todos os níveis, no século XXI.

\section{Referências}

ABERS, Rebecca; BULOW, Marisa Uon. Movimentos sociais na teoria e na prática: como estudar o ativismo através da fronteira entre Estado e sociedade. Sociologias, Porto Alegre, v. 13, n. 28, p. 52-84, set./dez. 2011. Disponível em: <http://www.scielo.br/pdf/soc/v13n28/04. pdf>. http://dx.doi.org/10.1590/S1517-45222011000300004.

AGONIA do Velho Chico aumenta com vazão ainda menor. Comitê da Bacia Hidrográfica do Rio São Francisco - CBHSF, 22.12.15. Disponível em: <http://cbhsaofrancisco.org.br/2017/ agonia-do-velho-chico-aumenta-com-vazao-ainda-menor/>. Acesso em: 09 jan. 2016.

BECK, Ulrich. Sociedade de risco: ruma a uma outra modernidade. 2. ed. São Paulo: Ed. 34, 2011.

BRASIL. Agência Nacional de Água - ANA. Conjuntura dos recursos hídricos: informe 2015. Brasília-DF: ANA, 2015.

Conjuntura dos recursos hídricos: informe 2016. Brasília-DF: ANA, 2016.

TCU, 2014

Tribunal de Contas de União - TCU. Referencial básico de governança. Brasília-DF:

CANOTILHO, J. J. G.; LEITE, J. R. M. Direito constitucional ambiental brasileiro. São Paulo: Saraiva, 2007.

DAGNINO, Evelina (Org). Sociedade civil e espaços públicos no Brasil. São Paulo: Paz e Terra. 2004.

DAMASCENO, Ângela P. D. Estudos sobre a implementação dos instrumentos de planejamento e gestão nas bacias hidrográficas do rio Salitre. Salvador: Ministério Público do Estado da Bahia, 2016. Nota Técnica 2016.

O enquadramento dos corpos d'água sob a perspectiva da participação social. 2013. Dissertação (Mestrado) - Escola Politécnica, Universidade Federal da Bahia, Salvador, 2013.

FACHIN. Zulmar; SILVA Deise Marcelino. Acesso à água potável: direito fundamental de sexta dimensão. 2. ed. Campinas: Milenium, 2012.

FLORES, Rafael Kruter; MISOCZKY, Maria Ceci. Participação no gerenciamento de bacia hidrográfica: o caso do Comitê Lago Guaíba. Rev. Adm. Pública, Rio de Janeiro, v. 42. n. 1. jan./fev. 2008. Disponível em: <http://www.scielo.br/pdf/rap/v42n1/a06v42n1.pdf>. http:// dx.doi.org/10.1590/S0034-76122008000100006.

GRAZIERA, M. L. M. Direito ambiental. São Paulo: Atlas, 2009. 
Direito das águas - trajetória legal, conflitos e participação social

GRAZIERA, M. L. M. Direito de águas doces: disciplina jurídica das águas doces. 2. ed. São Paulo: Atlas, 2014.

GUIVANT, Júlia Silva; JACOBI, Pedro Roberto. Da hidro-técnica à hidro-política: novos rumos para a regulação e gestão dos riscos ambientais no Brasil. Cadernos de Pesquisa Interdisciplinar em Ciências Humanas, Florianópolis, v. 4, n. 43, p. 2-26, jan. 2003. Disponível em: <https://periodicos.ufsc.br/index.php/cadernosdepesquisa/article/view/1950>. https:// doi.org/10.5007/1950.

HABERMAS, J. Era das transições. Tradução de Flávio Beno Siebeneichler. Rio de Janeiro: Tempo Brasileiro, 2003.

KHOURY, L. E. C. ARAUJO, P. (Org). Velho Chico: a experiência da fiscalização preventiva integrada na Bahia/ Equipe FPI. 1. ed. Salvador: Ministério Público da Bahia; CDLJ; Órgãos Parceiros do Programa FPI, 2014. 430f.

LEITE, José Rubens Morato Leite (Org.) Dano ambiental na sociedade de risco. São Paulo: Saraiva, 2012.

LOPES, José Sérgio Leite. Sobre processos de "ambientalização" dos conflitos e sobre dilemas da participação. Horizontes Antropológicos, Porto Alegre, v. 12, n. 25, p. 31-64, jan./jun. 2006. Disponível em: <http://www.scielo.br/pdf/ha/v12n25/a03v1225.pdf>. http://dx.doi.org/10.1590/S0104-71832006000100003.

MALVEZZI, R. Semi-árido: uma visão holística. Brasília: Confea, 2007. 147p.

MEDEIROS, Y. Participação social no gerenciamento de recursos hídricos: a bacia do São Francisco. São Paulo: ANABLUME, FAPESP, 2009.

NOBRE, M. Participação e deliberação na teoria democrática: uma introdução. In: COELHO, V.S.P.; NOBRE, M. (Orgs.). Participação e deliberação: teoria democrática e experiências institucionais no Brasil Contemporâneo. São Paulo: Ed. 34, 2004.

PACHECO, T. Racismo ambiental: expropriação do território e negação da cidadania. In: JUSTIÇA pelas águas: enfrentamento ao racismo ambiental. Salvador: Gráfica Santa Helena, 2008. (Caderno SRH - Serie Àgua e Ambiente, 2).

RIBEIRO, W. C. (Org.). Governança da água no Brasil: uma visão interdisciplinar. 1. ed. São Paulo: ANABLUME. FAPESP, 2009.

ROCHA, J. C. S.; SANTANA FILHO, D. M. Justiça ambiental das águas e racismo ambiental. In: JUSTIÇA pelas águas: enfrentamento ao racismo ambiental. Salvador: Gráfica Santa Helena, 2008. (Caderno SRH - Serie Àgua e Ambiente, 2).

; SERRA, O. (Orgs.). Direito ambiental, conflitos socioambientais e comunidades tradicionais. Salvador: EDUFBA, 2015. 
SANTILLI, Juliana Ferraz da Rocha. A Política Nacional de Recursos Hídricos (Lei 9.433/97) e sua implementação no Distrito Federal. Rev. Fund. Esc. Super. Ministério Público Distrito Federal e Territórios, Brasília, ano 9, v. 17, p. 144-179, jan./jun. 2001.

TATAGIBA, Luciana. Os conselhos gestores e a democratização das políticas públicas no Brasil. In: DAGNINO, Evelina (Org.). Sociedade civil e espaços públicos no Brasil. São Paulo: Paz e Terra, 2004.

VIEGAS, Eduardo Coral. Gestão da água e princípios ambientais. 2. ed. Porto Alegre. EDUCS - Editora da Universidade de Caxias do Sul, 2012.

Visão jurídica da água. Porto Alegre: Livr. do Advogado Ed., 2005.

ZHOURI, A. Justiça ambiental, diversidade cultural e accoutability - desafios para a governança ambiental. Revista Brasileira de Ciências Sociais, v. 23, n. 68, p. 97-107, out. 2008. Disponível em: <http://www.scielo.br/pdf/rbcsoc/v23n68/v23n68a07.pdf>. http://dx.doi.org/10.1590/S0102-69092008000300007.

Julio Cesar de Sá da Rocha - Pós-Doutor em Antropologia pela Universidade Federal da Bahia (UFBA); pós-doutor em Pós-Doutorado Sanduíche pela Tulane University (Estados Unidos); doutor e mestre em Direito pela Pontifícia Universidade Católica de São Paulo; graduado em Direito pela UFBA (2000). Diretor da Faculdade de Direito da UFBA; professor adjunto IV. Salvador/BA, Brasil. E-mail: juliorochaufba@gmail.com.

Luciana Espinheira da Costa Khoury - Mestranda do Programa de Pós-Graduação em Direito Ambiental da Universidade Federal da Bahia (UFBA); graduada em Direito pela UFBA. Promotora de Justiça e coordenadora do Núcleo de Defesa do Rio São Francisco do Ministério Público do Estado da Bahia; coordenadora do Fórum Baiano de Combate aos Impactos do Agrotóxico. Salvador/BA, Brasil. E-mail: luciananusf@gmail.com.

Ângela Patrícia Deiró Damasceno - Doutoranda em Sociologia pela Universidade Federal de Sergipe; mestre em Engenharia Ambiental Urbana pela Universidade Federal da Bahia (UFBA); especialista em Política e Estratégia pela Universidade do Estado da Bahia; graduada em Ciências Sociais pela Universidade de Salvador. Consultora Técnica do Ministério Público da Bahia. Salvador/BA, Brasil. E-mail: angelapdd@yahoo.com.br. 